\title{
Caracterização de Estirpes Gram-Negativas Isoladas de Queijos e Avaliação da Produção de Substâncias Antimicrobianas
}

Iuri Lourenço Marinho (I), Thomaz Rocha Cupertino (I), Hugo Figueiredo Botelho Damaceno (I), Claudinei Vieira de Freitas Junior (I), Rodrigo Barcellos Revorêdo Silva (I), Leonardo Emanuel de Oliveira Costa (I), Janaína dos Santos Nascimento (I)

(I) IFRJ - Instituto Federal de Educação, Ciência e Tecnologia do RJ (Rua Senador Furtado 121- Maracanã - RJ)

\section{Resumo}

Agentes infecciosos Gram-negativos como Aeromonas, Escherichia, Salmonella, Yersinia e Pseudomonas são dificilmente inibidos por bacteriocinas produzidas por bactérias Gram-positivas, as mais estudadas atualmente. Devido a este fato, surge a importância do estudo de substâncias antimicrobianas (SAM) produzidas por bactérias Gramnegativas que sejam ativas contra estes micro-organismos. Neste trabalho, cerca de cinqüenta estirpes Gram-negativas foram isoladas de queijo, mas somente as que foram produtoras de algum tipo de SAM foram caracterizadas. Quinze estirpes (Q2, Q3, Q4, Q5, Q15, Q22, Q29, Q33, Q34, Q35, Q37, Q38, Q44, Q45, Q46) mostraram ser produtoras de SAM e foram identificadas através do sistema comercial Bactray ${ }^{\circledR<}$, como pertencentes a diferentes espécies como Enterobacter sakazakii, Acinetobacter baumannii, Escherichia coli e Yersinia intermedia. As 15 estirpes produtoras foram submetidas ao antibiograma, onde todas se mostraram resistentes a pelo menos um antibiótico testado. As estirpes Q5, Q29, Q37, Q38, Q44, Q45 e Q46, entretanto, foram resistentes a pelo menos três antibióticos de diferentes classes, apresentando assim, um perfil típico de multi-resistência. As estirpes também foram submetidas à avaliação do perfil plasmidial. Todas as 15 estirpes produtoras de SAM

\footnotetext{
Referência:

luri Lourenço Marinho, Thomaz Rocha Cupertino, Hugo Figueiredo Botelho Damaceno, Claudinei Vieira de Freitas Junior, Rodrigo Barcellos Revorêdo Silva, Leonardo Emanuel de Oliveira Costa, Janaína dos Santos Nascimento. Caracterização de Estirpes Gram-Negativas Isoladas de Queijos e Avaliação da Produção de Substâncias Antimicrobianas. In: Anais do $1^{\circ}$ Congresso Latinoamericano de Microbiologia e Higiene de Alimentos MICROAL 2014 [= Blucher Food Science Proceedings, num.1, vol.1]. São Paulo: Editora Blucher, 2014. DOI 10.5151/foodsci-microal-271
} 
apresentaram diversas formas plasmidiais, sendo a maioria destas com tamanho variando de 1 a $10 \mathrm{~kb}$. Interessantemente, ao se avaliar o potencial de aplicação contra diferentes patógenos associados a alimentos, observouse que as 15 estirpes, mesmo pertencendo a espécies distintas, apresentaram o mesmo espectro de ação, inibindo todas as estirpes de E. coli e Salmonella testadas. Apesar de restrito, o espectro de ação apresentado pelas estirpes produtoras de SAM é de extrema importância para a área de alimentos, uma vez que E. coli e Salmonella representam as bactérias Gram-negativas mais associadas às DTA's (doenças transmitidas por alimentos). Buscou-se, então, verificar se as estirpes eram capazes de produzir SAM em meio líquido. Para isso, o sobrenandante das culturas crescidas em caldo foi obtido por centrifugação, filtrado, diluído seriadamente e testado contra as estirpes indicadoras. A estirpe Q3 foi a que apresentou os melhores resultados, apresentando um título de 800 $\mathrm{UA} / \mathrm{ml}$. Outros experimentos associados à produção de SAM em meio líquido ainda estão em andamento.

Palavras-Chave: substâncias antimicrobianas, Gram-negativas, queijos, multi-resistência, Salmonella

Agência de Fomento: FAPERJ, IFRJ 